\title{
Clinical Dentistry Research Compendium
}

\author{
Language: English \\ ISSN: 978-1-62257-574-9 \\ Edition: $1 / \mathrm{e}$ \\ Publish Year: 2013 \\ Pages: 411, illustrated \\ Price: $\$ 220.00$
}

Author: Giuseppe Alessandro Scardina Publisher: Nova Science Publishers, Inc.

This book compiles the articles published in Volume 4 of the International Journal of Clinical Dentistry. The book is a multidisciplinary forum for publications from all fields of dental medicine. This book builds a bridge between basic and clinical sciences, promoting the exchange of information and progress of dental medicine for the benefit of patients and clinicians. It offers comprehensive coverage of new techniques, important developments, and innovative ideas in all fields of clinical dentistry.

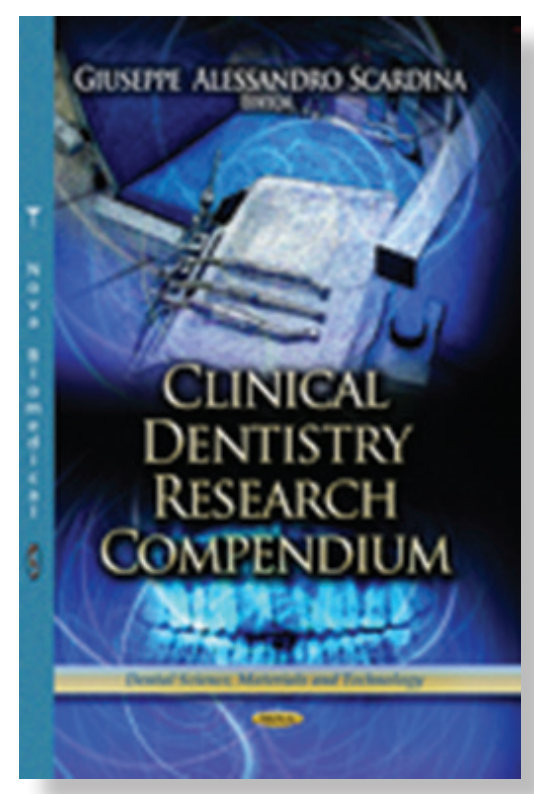

https://doi.org/10.25241/stomaeduj.2016.3(1-2).bookreview.2

Marian-Vladimir Constantinescu,DDS, PhD

ROPOSTURO-HolisticDental Medicine Institute, Bucharest, Romania

e-mail: dr.vladimir.constantinescu@gmail.com

The Book Review is drafted in the reviwer's sole wording and illustrates his opinions. 